\title{
Developing professional status: an investigation into the working patterns, working relationships and vision for the future of UK clinical dental technicians
}

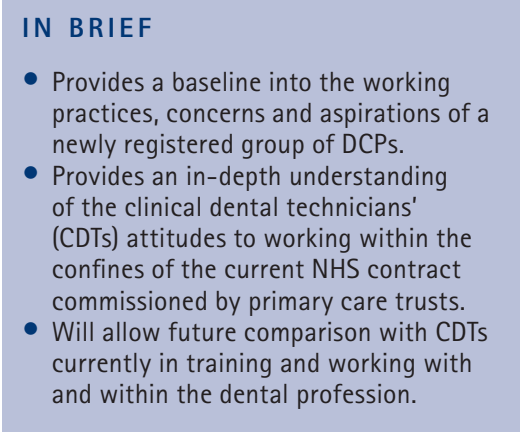

\section{VERIFIABLE CPD PAPER}

\begin{abstract}
Aims To investigate the working patterns and patient base of registered clinical dental technicians (CDTs); their relationships with dentists and other professionals in the dental team; their willingness to work within the NHS and their expectations for the future as a new professional group. Methods Face-to-face qualitative interviews of registered CDTs, selected because of their geographic representation and mode of working, informed the development of a postal questionnaire survey of all early registrants with the General Dental Council (GDC). Results The majority of CDTs reported working part-time, often combining clinical practice with their role as a dental technician. They reported both positive and negative working relationships with dentists and dental technicians, demonstrating collaboration and/or competition depending on whether the scope of CDTs was respected and patient care was shared or lost. CDTs role in the NHS was limited because they did not have the status of becoming a recognised provider of dental care. There was a desire to expand their scope of practice in future. Conclusion CDTs are embracing their new status as an occupational group within dentistry. Core features of becoming a professional group were exhibited including the importance of social and financial status and the need to negotiate their current and future roles in the healthcare system.
\end{abstract}

\section{INTRODUCTION}

In 1993 the Nuffield Foundation reported on the Education and training of personnel auxiliary to dentistry. ${ }^{1}$ The report recognised that various organisations representing dental technicians had over a long period made representations to government (within the UK) to allow them to undertake the clinical stages of denture construction in addition to providing the technical support to dentists.

The Nuffield report suggested that there were a number of technicians that were seeing patients illegally and that the illegal practice of a trade or profession was not in the public interest. ${ }^{1}$ They further

\footnotetext{
'King's College London Dental Institute at Guy's, King's College and St Thomas' Hospitals, St Thomas Street, London Bridge, London, SE1 9RT; ${ }^{2}$ Oral Health Services Research and Dental Public Health, Denmark Hill Campus, Caldecot Road, London, SE5 9RW; ${ }^{3}$ The University of Portsmouth Dental Academy, Faculty of Science, University of Portsmouth, Portsmouth, Hampshire, P01 2UP

*Correspondence to: Dr David Radford

Email: david.radford@kcl.ac.uk
}

Online article number E3

Refereed Paper - accepted 1 October 2012

DOI: 10.1038/sj.bdj.2013.55

${ }^{\circledR}$ British Dental Journal 2013; 214: E3 stated 'non-enforcement of a law introduced in the public interest is equally undesirable. The law should be enforced, revoked or revised.' ${ }^{1}$ They then recommended a change in the law associated with a programme of training for clinical dental technicians (CDTs). The Government and the General Dental Council (GDC) supported this decision not least because of a long-standing desire to legalise the activities of dental technicians. ${ }^{2}$ The law was changed in line with the Nuffield report and the GDC recognised CDTs as a profession complementary to dentistry (now known as dental care professionals) in 2007. Registration with the GDC opened in July 2006 and when this present study was conducted between February 2009 and July 2010, 92 were registered to practice. It appears that there are currently no plans to train CDTs in significant numbers as there is no presumption by the UK Government that large numbers of CDTs will be required. ${ }^{2}$ This is despite the argument that their training in complete denture construction is more thorough than that received by dental students. For example, in Canada, it was reported that, denturist
(CDTs) students treated up to 25 times as many denture patients as dental students. ${ }^{3}$ In the UK, Hancock argued in favour of the introduction of CDTs suggesting that dentists would welcome their introduction ${ }^{4}$ given the reduction in dental undergraduate teaching on complete dentures in the UK. ${ }^{2,5,6}$ Both of the above have implications for the quality and volume of appropriate patient care.

CDTs' current scope of practice is defined by the GDC and includes providing whole patient care for complete dentures cases while only providing removable partial dentures on the prescription of a dentist. ${ }^{7}$ Professional theory also highlights the issue of 'jurisdiction' or what is termed the 'scope' of a professional group is important, as contests over care within and between professional groups are one aspect of professional life. ${ }^{8}$ This project highlights the challenges of a shared jurisdiction between dentists and CDTs.

It is important to look at the development of CDTs in the context of the sociology of professions, particularly how they develop and maintain their status and power in the social and financial 
order within society. A particularly helpful dynamic theory developed by Larson ${ }^{9}$ and utilised by Macdonald ${ }^{10}$ terms this as a 'professional project', that is, the project of becoming and staying a professional group. Insight into the clinical practice, working relationships and relations with the National Health Service of registered CDTs will aid understanding of just how they have espoused their professional role and the level of competition and negotiation required to develop this further. Comparatively little has been published on this topic. ${ }^{11,12}$ Ross et al. ${ }^{11}$ surveyed CDTs before their practice was legalised. This current project provided the opportunity to follow up and examine this emerging professional group on their views in relation to the state, other professional groups and patients and their expectations for the future.

\section{AIMS}

The aims of this current study were to investigate reported working patterns and the patient base of registered CDTs; their roles and relationships with dentists and other professionals in the dental team; their willingness to work within the NHS to deliver care and their expectations for the future as a new professional group.

\section{MATERIALS AND METHODS}

This investigation used mixed methods: a qualitative (in-depth interviews) and a quantitative (postal questionnaire survey) study. King's College London Ethics Committee approved the protocol for this research project (BDM/09/10-22).

\section{Qualitative study: in-depth interviews}

The addresses of 92 CDTs registered in the UK in March 2009, obtained from the GDC, were mapped (Fig. 1) and purposively sampled on the basis of geographical spread, sex, having an independent practice or colocated with general dental practitioners (GDPs) and whether they were in rural or urban areas to achieve a spread of informants. The latter were identified on the basis of identical work addresses on the GDC list of CDTs. Thus, a heterogeneous sample of seven CDTs, which included widely varied characteristics, was invited to participate by letter. After a one-week interval, they were followed up by telephone to provide

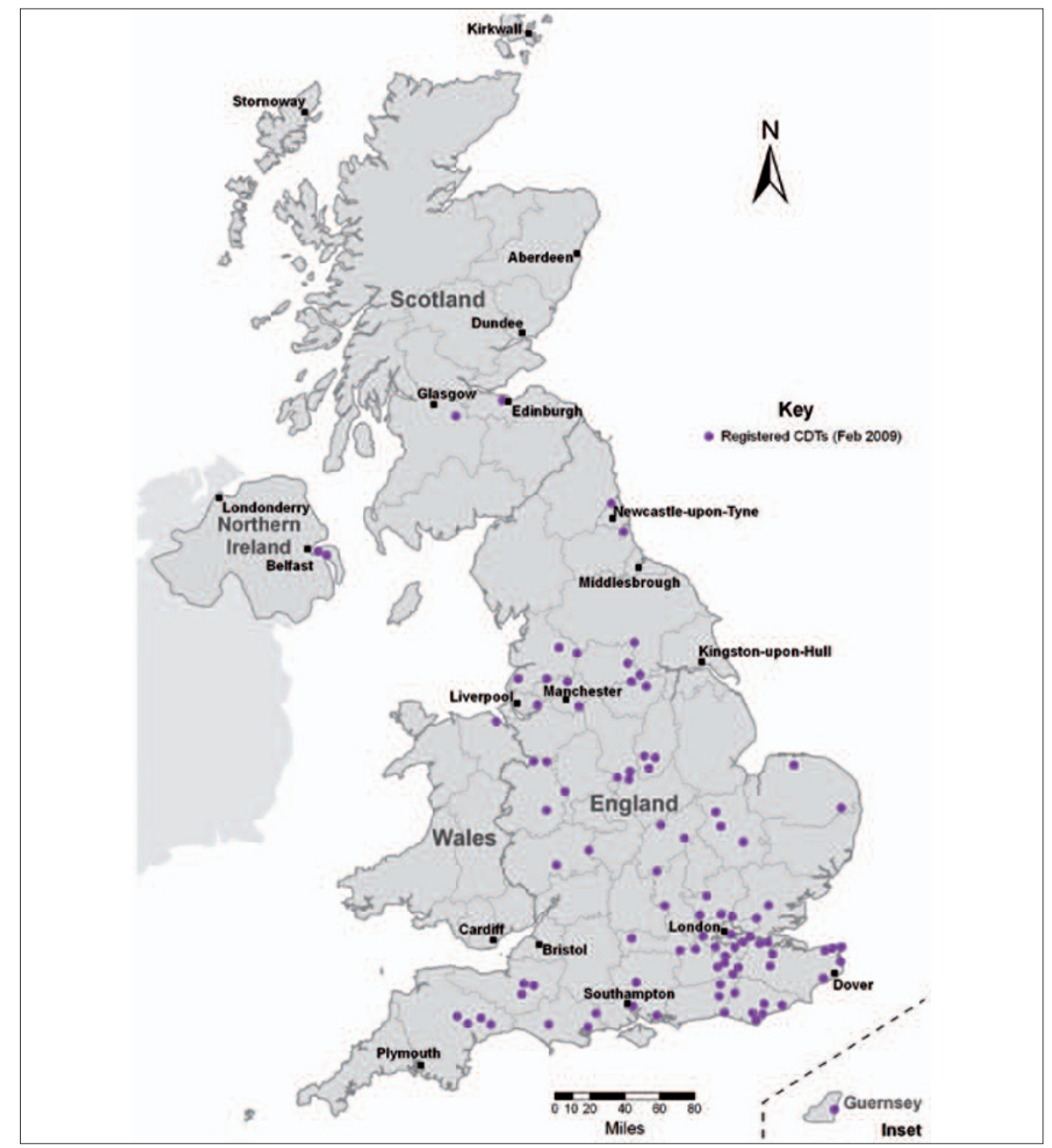

Fig. 1 Geographical location of registered CDTs in the UK (March 2009)

additional information about the study and the CDT was asked whether he/she would participate. The in-depth interview was held at a place most convenient to the CDT. Informed written consent was obtained before commencement of the interview. A topic guide was utilised to standardise data collection. Informants' views were recorded and additional field notes were made by the interviewer (WL). Data were then transcribed verbatim. Analysis was undertaken using Framework Methodology, ${ }^{13}$ which is a matrix-based method for ordering and synthesising data. An index of themes was developed, following which line-by-line indexing of the data occurred. Subsequently data were sorted by theme and synthesising of the data was undertaken to achieve explanatory summaries.

\section{Quantitative study: questionnaire survey}

The addresses obtained from the GDC of the CDTs registered in the UK in March
2009 were used to map the geographical distribution of CDTs. A questionnaire was drafted to address the objectives of the study based on the published literature and the findings of the qualitative interviews.

The final questionnaire had 32 questions divided into six sections: working pattern, patient base, working relationships, the NHS and vision for the future and their personal details. Two separate mailings were sent out with a four-week interval between them. The survey was conducted anonymously. To increase the return, and in line with previous research into 'denturists' of New Zealand, a prize draw was included. By the beginning of June 2010, 39 completed questionnaires were received; data were inserted into an Excel program and analysed descriptively.

\section{RESULTS}

In the UK, 92 clinical dental technicians were registered with the GDC in March 2009, of whom 90 were male and 2 female. A higher concentration of CDTs 


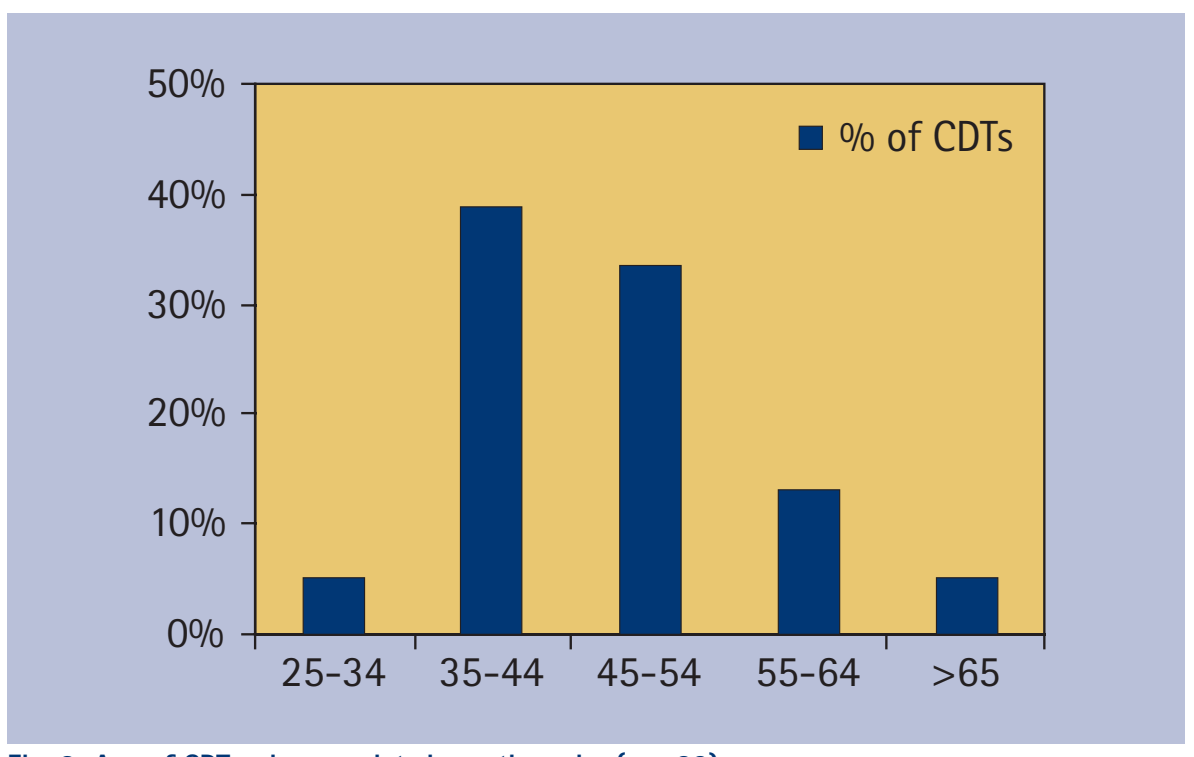

Fig. 2 Age of CDTs who completed questionnaire $(n=39)$

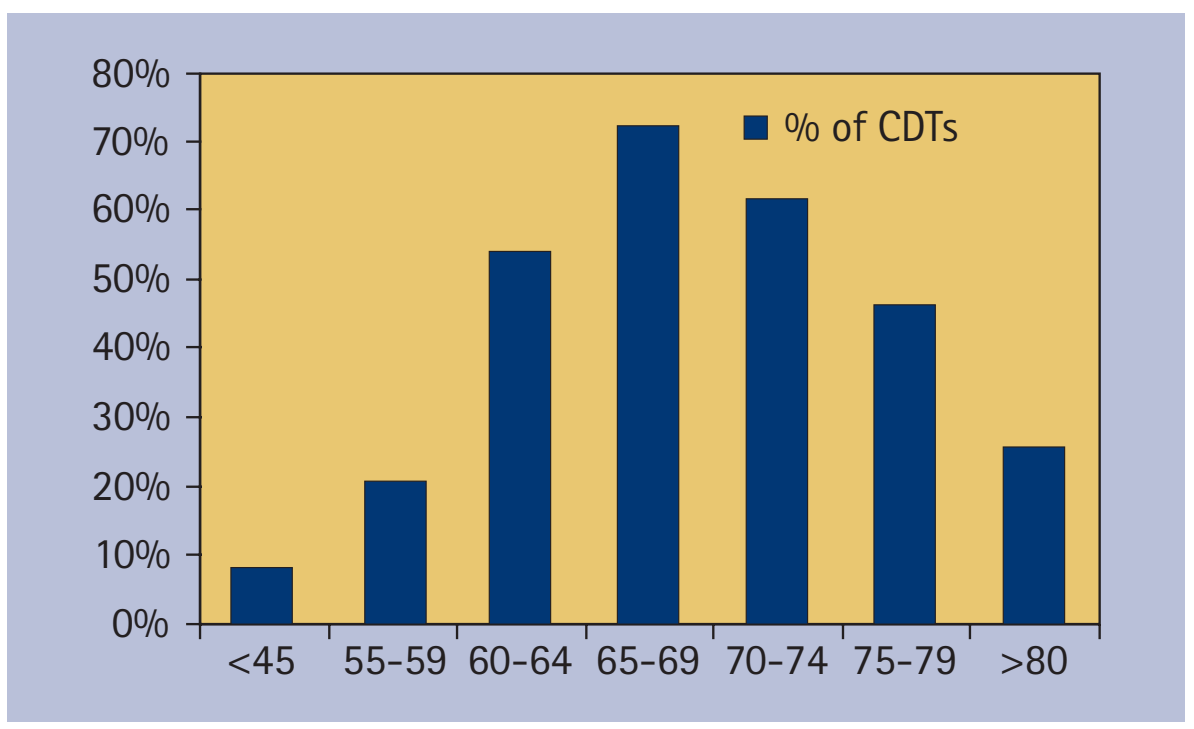

Fig. 3 Age of main groups of patients treated

were based in the South East of England. Two CDTs were established in Scotland, two in Northern Ireland and one in the Channel Islands. There were none in Wales (Fig. 1). The seven CDTs that participated in the qualitative study and the 39 that responded to the postal questionnaire comprised up to $50 \%$ of the profession. The findings from the two aspects of the study are integrated under the relevant headings below.

\section{Demography of respondents}

The majority of respondents were in the 35-54 year age-band (Fig. 2) and from the South East of England, followed by CDTs from the South West and the North West. No questionnaires were returned from Northern Ireland or the North East of England.

\section{Professional status}

There was a positive view about their role in providing patient care as a registered clinician as demonstrated by the following quotation:

'I find it is a fantastic thing to be qualified, to be registered - and I feel proud about that'. [CDT2:4 - NB: CDT is identified by number and the section/page of the transcribed interview]

\section{Patient base}

Figure 3 shows the distribution of the agegroups of patients reported to be treated by CDTs.

Most reported seeing patients of various socio-economic backgrounds; however, $34 \%$ catered mainly for patients who they labelled as financially better off. Seven out of ten respondents (70\%) estimated that between 50\% and 70\% of their clinical care consisted of constructing complete dentures.

There were four groups of patients that some CDTs were not prepared to see as they did not feel competent or fully trained, namely patients with dementia, a complex medical history, needing domiciliary visits and those confined to bed (Fig. 4). This was illustrated during the qualitative interviews where CDTs felt these groups would be better treated by dentists because of their additional training:

'Patients with dementia or medically compromised should really be seen by a dentist'. [CDT4:3]

'For special needs patients you need extra training'. [CDT5:2]

\section{Working relationships}

Working relationships were explored with other members of the dental team, starting with dentists, highlighting elements of collaboration and competition. Over half of respondents (56\%) received between one and six referrals a month from dentists and only $29 \%$ of CDTs indicated that they had not received a referral from a dentist for the previous month. It seemed to be common for some to work with several dentists, with over 50\% working with between two and four dentists. Just under half (44\%) of CDTs had referred one or more patients to a dentist for the construction of a denture over the previous two years. For single-handed CDT practices, word of mouth seemed to be a major 
factor in recruiting new patients whereby referrals from dentists formed only a small or non-existing part of the monthly patient in flow. Besides personal recommendation, the radio, internet, local papers, the yellow pages and high end glossy magazines were mentioned as additional sources of patients.

There was evidence of growing collaboration and status with dentists. For some they now had begun to feel part of the dental team, at least some of the time:

'Yeah I would say so. I would have said 'not' about six months ago. Now I'm working together with a couple of dentists, I'm starting to feel... sometimes yes and sometimes 'no.' [CDT2:3]

Most CDTs interviewed felt there was little competition with dentists over the construction and delivery of dentures in terms of quality. They highlighted the concerns over the ability of dentists, particularly younger dentists, to provide care as demonstrated by the following quotations:

'The quality of dentures of dentists is so poor. I don't think dentists are interested in dentures'. [CDT 2:2]

'If the way undergraduate dentists are being taught in dental hospitals involves less and less practical hands-on treating patients for the provision of partial dentures then somebody will have to take up the possible shortfall'. [CDT6:15/16]

It was generally recognised that many dentists did not like making dentures and that there was the need to work with dentists, not against them:

'I have got to work with rather than against them or in competition with them.' [CDT5:7]

There was evidence of active team working in one dental practice where the CDT worked on site, combined with patient empowerment:

'The patients in the NHS practice where I work are given the option and can either be treated by their dentists who would make them a new set of dentures or else they have the option of coming to see the clinical dental technician... The dentist will explain to the patient who I am and if they decide, yes, they want me to make them, an appointment is made for me to treat them.' [CDT6:13]

One of the barriers to working with dentists, identified through the interviews, was that many dentists believed their work was

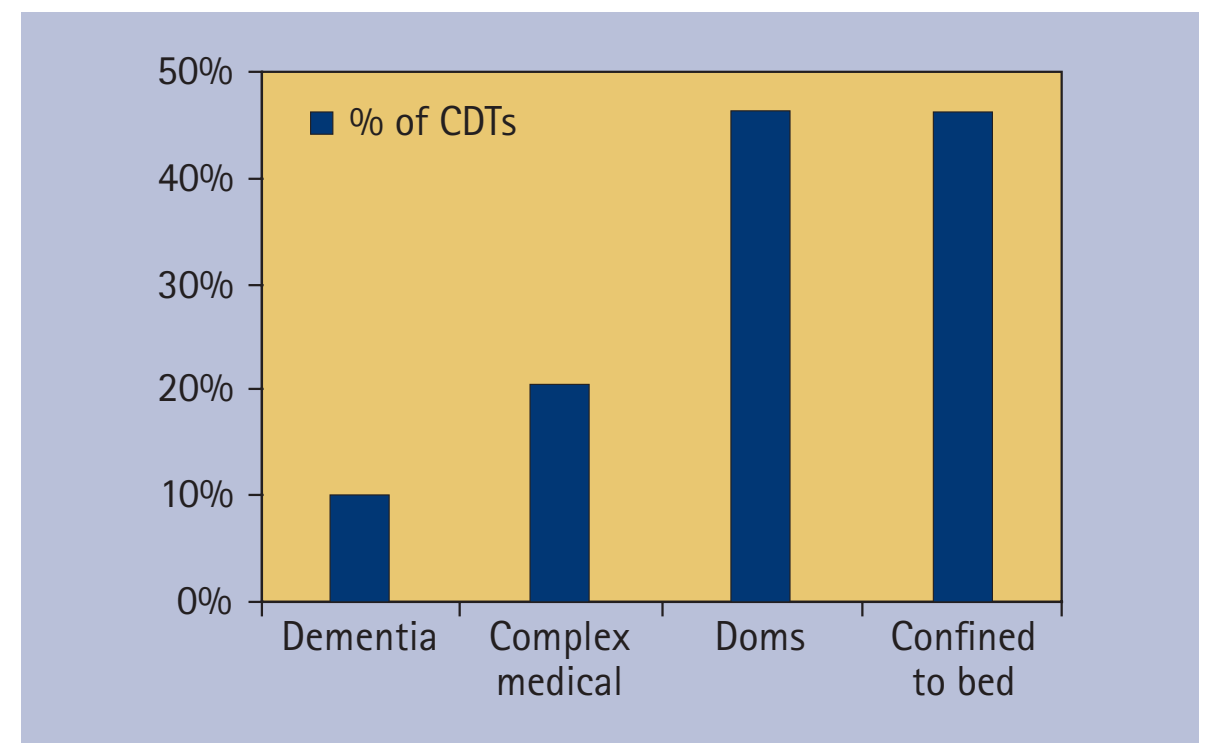

Fig. 4 Types of patients not treated by CDTs $(n=39)$

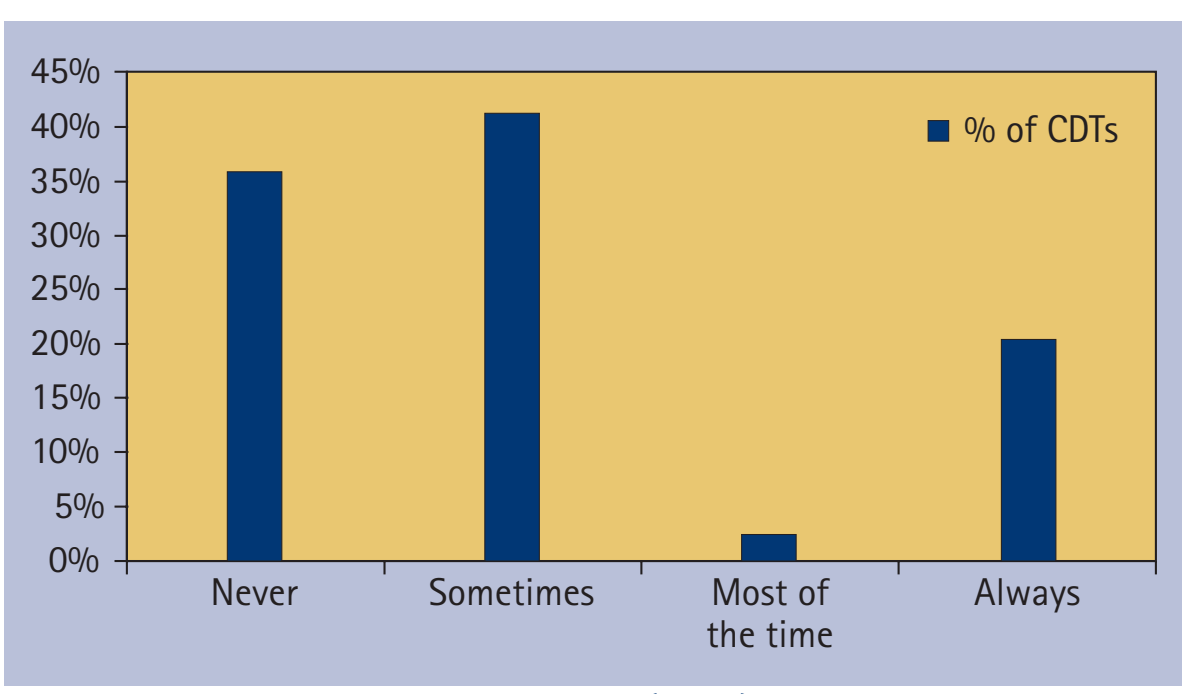

Fig. 5 Routine working with a dental nurse by CDTs $(n=39)$

illegal. Furthermore, the issue of referrals and treatment plans for partial dentures was quite sensitive - CDTs reported losing patients to dentists when requesting a treatment plan. Sometimes dentists even accused them of illegal practice. The treatment plans received from dentists were reported to be very limited and of no real benefit to the CDTs:

'They [dentists] do not write treatment plans - it is basically a quick note: Make a partial denture for Mrs Smith. A covering letter to say: go ahead'. [CDT5:13]

'There is a certain dentist that won't return the patient'. [CDT7:8]

'[A] lot of professionals are ringing me up sometimes. What [you are] doing is illegal - and that is a professional dentist. I then get a patient in who says 'I have been to my dentist and you can't make dentures it is illegal'. No you can, you don't understand the law, it is for partials you need a prescription, not fulls... I get that quite $a$ lot and that is just a lack of knowledge'. [CDT2:9]

Interviewees indicated that patients and the public know little about them and even other members of the dental team were unaware of their scope of practice; highlighting that more is needed to be done to raise awareness of their existence and role:

'When I see a patient in the surgeries where I work they think I'm a dentist'. [CDT6:13]

'I do get people asking if I do fillings'. [CDT3:10]

'I think there should be more, more information around for people to understand who we are and what we are as a profession and give patients more information as well... because they don't know we exist as a profession.' [CDT2:9] 
CDTs demonstrated a range of different relationships with dental technicians from collaboration where they employed dental technicians on the premises through working independently to being direct competition:

'I am not the sort of person that just wants to do the clinical work and ignore the technical side because I think we should be seeing it from start to finish. There will always be a balance between the two.' [CDT3:2]

Where there was agreement among CDTs was that they perceived themselves to be in direct competition with illegally practising dental technicians who were undermining their practice. The opinion of CDTs about dental technicians illegally providing dentures to the public was quite clear: they should train and register otherwise they should face prosecution. CDTs recognised that training was absolutely essential to deliver high quality dentures. Some tried to alert the GDC about illegally practising individuals but it was generally felt that this did not lead to an end of this practice. It was felt this practice existed all over the country, supported by advertising. One CDT was convinced that at least half of the dental laboratories in each city or town participated:

'There is loads advertising'. [CDT 2:4]

'Every dental technician I have worked with has made dentures illegally. It is huge.' [CDT 4:9]

\section{Working with a dental nurse}

During clinical sessions, CDTs varied in their use of a dental nurse (Fig. 5). Only $21 \%$ always had two registered members of the dental team present. The most common reasons for not having a dental nurse were that they did not see the need, had only a limited amount of work for them to do and because of this the cost of having a dental nurse was too great. However, many of them perceived having a dental nurse as something to aspire towards:

'If I get much busier, I might have to take on a nurse or a practice manager or something like that'. [CDT5:6]

\section{Working for the NHS}

Status or lack of it within the NHS was a major barrier to providing care as CDTs are not legally recognised as providers within the NHS and therefore unable to contract with Primary Care Trusts or join the performers list in England, where the majority of CDTs reside. Only one of the respondents worked within the NHS. Opposition from dentists, the complexity of the current payment system of UDAs and the low fees paid for NHS services were considered by CDTs to undermine the quality of the work that can be provided. Responses were not all negative. Some CDTs would have liked to provide dentures for NHS patients, but with the remuneration system they felt this would have been impossible as demonstrated by the following quotations:

'I came across some National Health dentists that will not use special trays - that will churn out whatever, they don't care what it looks like, what it fits like... where I have come across [dentists] that will spend time [you ask] how the hell do they make it worthwhile?' [CDT3:6/7]

'It is a lot of work for not an awful lot of gain. [Laughs] You are hearing this a lot, aren't you?' [CDT5:5]

'Doing NHS is almost like a loss leader. We are prepared to do a bit of the NHS to pull in some of the private work'. [CDT4:4]

Besides the financial constraints, CDTs cited several barriers for taking up NHS work. As independent providers they felt they should be able to bid for a contract with the PCT and not be dependent on dentists. CDTs working together with NHS dentists found it difficult to decide on the breakdown of the fee for the Band 3 treatments in England, which besides the prosthetic work could have included restorative, periodontal treatment and oral surgery.

'How do you work out what the filling is worth and what the denture is worth?' [CDT 3:5]

'I believe there is an awful lot of paperwork that nobody likes.' [CDT 5:4/5]

'I don't see why the CDT shouldn't be able to negotiate his/her own contract directly. Otherwise there is an amount of control [by the dentist]. [CDT 7:6]

NHS work was perceived as a possible initial training period where the ultimate goal was to move into private practice once sufficient skills were developed or as a loss leader to attract private work. However, for others providing NHS care was taking place or an aspiration in response to need:

'We should be providing NHS dentures, especially because through my visits to old peoples' homes [I've seen] many patients there that should have their dentures updates and they are not. They are not even being seen at all... I approached a PCT on that fact and they said funding is not available.' [CDT7:5]

Thus the findings suggest that relationship with the state through the NHS is limited by a lack of status in the system and the ability to achieve greater remuneration within the private sector.

\section{Future vision}

\section{Scope of practice}

The desire for a change in the scope of practice as set out by the GDC was overwhelming in the questionnaires (90\%) and in all interviews. The main demand was for independent provision of removable partial dentures. Several CDTs refer to themselves as being 'specialists' in denture provision and therefore consider that they should be able to work independently with direct access for the provision of removable partial as well as complete dentures. This was followed by a request to be allowed to prepare teeth for removable partial dentures (guide planes, rest seats), permission to provide tooth whitening and to provide prosthetic treatments for patients with clefts. The option of only allowing CDTs to provide prosthetic treatments and take this type of treatments away from dentists was also proposed:

'We should be trained to be able to see whether to begin a partial rather than wait for a referral from a dentist. It slows the whole thing down really.' [CDT2:5]

There were divided views over certain elements of their current scope of practice: whereas some did not see the value of CDTs being trained to take radiographs where they saw dentists as more experienced, other CDTs saw this skill as an essential tool for the provision of removable partial dentures. None of the single-handed CDTs interviewed had X-ray facilities at their disposal and were not inclined to purchase them in the near future:

'I was trained to do radiography, but I think there are people who are probably better at it than me. I cannot say I am a competent radiographer'. [CDT 1:9]

'I do not see the use for that. If I bought the $X$-ray machine it would be ridiculous. If I need the information I will send them to a dentist for that'. [CDT2:9] 
Training and continuing professional development

In general CDTs were anxious about the future provision of basic training. They were worried about future training places but were quite happy with CPD provision:

'There are quite a few courses. CPD I'm talking for me. Some have been a bit poor, some have been excellent.'[CDT 2:5/6]

The main request for changes in the scope of practice was the provision of partial dentures without a prescription. Some CDTs acknowledged that this could not be introduced without additional training:

'That's the bit that is ridiculous [the prescription]. I have patient who lost their denture and wants a denture made in 48 hours and then we need to get a prescription made up and all that.' [CDT2:18]

The CDTs interviewed indicated that a possible ideal set-up of their practice would be in conjunction with a dentist, stressing the benefits of collaboration; however, the merits of working singlehanded were also recognised:

'I only ever plan to work in dental practices where there are members of the dental team around. [CDT1:4]

'Ideally CDTs should be working in practices with on site dentists... Patients don't feel they have got to get another check-up somewhere. The dentist is there and doesn't mind just popping in'. [CDT3:13]

\section{DISCUSSION}

The location of these CDTs, who were early registrants with the GDC, was analysed based on their registered address. The findings indicate that CDTs were mainly located in the south east of England, which is the area of highest population dentistry in the UK but also where a lower proportion of the population is edentulous. ${ }^{14,15}$ In contrast, areas such as the north of England, Scotland and Wales where edentulousness is higher had few or no CDTs. Furthermore, epidemiological surveys suggest that the largest need for CDTs would seem to be for older, socioeconomically disadvantaged people. The latter are more likely to seek NHS rather than private provision. ${ }^{16-18}$ This contrasts markedly with the reported patient base of CDTs, which is the more affluent and 'younger' age-band of old people who largely receive care in the private sector. This research has demonstrated that only selected patient groups were seen on the basis of financial and physical characteristics.

The level of time spent in clinical practice, as opposed to technical work, is an interesting point of discussion with just over half of respondents (56\%) spending half or more of their time in clinical practice. The more time spent with patients the less time they would have to do the technical work. Several CDTs stressed that the idea of legalising their profession was to provide better prosthetic services where one person would be responsible for the clinical work as well as the technical work. This idea did not seem to be widely adopted as some employed dental technicians to execute some or all of the laboratory stages. In addition, this way of providing dental prosthetic services renders invalid the past economic argument put forward in the USA and Finland that the introduction of CDTs would lead to cheaper dentures by cutting out the middle person. ${ }^{3}$

CDTs are increasingly recognised as established members of the dental team and are negotiating their roles with others in the system as is the norm for professional groups. ${ }^{10}$ This negotiation takes the form of collaboration and competition. They reported both positive and negative working relationships with dentists and dental technicians, demonstrating collaboration and/or competition with dentists and dental technicians depending on whether the scope of CDTs is respected and patient care is shared or lost.

This study was conducted between February 2009 and June 2010. Since that date there are 226 CDTs registered with the GDC (December 2011). These newer registrants, educated within the UK, may have a different perspective and have adopted different working practices as the profession evolves. However, when interviewed and surveyed in this study CDTs were often working single handed without a dental nurse present. It appears that although this important element of quality care may not be present for all CDTs, it remains an aspiration for some CDTs as their career and business develop. Nevertheless, most CDTs thought the ideal set-up of practice would be working as part of the dental team or working with a dentist. The GDC guidelines Principles of dental team working ${ }^{19}$ state: 'when treating patients, make sure there is someone else - preferably a registered team member - present in the room, who is trained to deal with medical emergencies', yet 79\% of CDTs questioned in our research did not always work together with a dental nurse. Often they would be by themselves in the surgery together with the patient. They quoted cost as an important factor. Twenty-five years ago in 1985 Lynn $^{20}$ argued this would be a major problem.

The view, that CDTs are better at providing prosthetic care than dentists was a recurring theme during the interviews. CDTs argued that dentists lack sufficient technical knowledge about the construction of dentures, which seemed to correspond with the reduction in teaching of the technical aspects in prosthetic dentistry. ${ }^{2,5,6}$ According to this research, the introduction of CDTs as registered members of the dental team has not stopped illegal practice of the provision of dentures. Moreover, registered CDTs indicated that many dental laboratories all over the country still provided this type of service. In the opinion of the CDTs interviewed any attempt made by registered CDTs in stopping this practice by contacting the GDC did not seem to have much effect. This appears to undermine their status and effort in becoming trained and registered and fails to protect the public; hence their association airing concerns on this topic. ${ }^{21}$

Acceptance by the public is an important dimension of becoming a professional group. ${ }^{10}$ At the time of the research, CDTs indicated that the public was not aware of their status and sometimes thought they were dentists, while others were led to believe that they were illegal. Achieving public and professional acceptance were important issues to CDTs and are important steps in the development of a profession.

CDTs often did not feel remuneration for prosthetic treatment under the NHS would be sufficient for them to provide good quality denture work, however, this is expected of dentists. Another barrier to uptake of NHS treatment provision was the inflexibility of the English administrative system of Primary Care Trusts (PCTs) where CDTs were not able to get a direct contract or get included on the performers list. In addition, PCTs contract for dental services and not for specific elements of a course of treatment, therefore contracting with 
dentists is the current practice. Despite CDTs being able to get a steady flow of patients, difficulties arose for the calculation of remuneration of their work. When several treatments need to be provided, it becomes complex to divide the money for the course of treatment between the dentist and the CDT.

During the interviews, the tension between status and financial remuneration was evident and the reluctance to take NHS type of work compared with the private sector was explored. Dentures have not been considered commercially viable on the NHS by GDPs and many have historically begun to provide them privately. Hence, it would appear that CDTs main source of income is from a less viable component of NHS dentistry. Clearly there is a need to ensure that older people, who are often less financially affluent should be able to obtain dentures from the NHS and therefore steps should be taken to develop a commercially viable contract model for CDTs to provide NHS care. However, in doing so there is a need for realism in that there are few CDTs in the country and while there is sufficient private potential, there will be less incentive to provide NHS care.

Negotiations with the state, patients and other dental professionals are part of professional life ${ }^{10}$ and as demonstrated by this study, policy, financial and administrative restraints have limited CDTs' participation in the NHS in England. CDTs mainly provide complete dentures but a number would like to expand their scope of practice, extending it further in relation to removable partial dentures.

One of the strengths of this research is the fact that it uses mixed methods, both qualitative and quantitative research. The main limitation of this research is the low response rate to the questionnaire survey. This could be for a number of reasons, which include a history of working as individuals rather than as part of a system, the timing of the survey and its perceived relevance to the recipients. However, overall around half of the registered CDTs in the UK at the time would have participated in the study so its findings should not be ignored. As CDTs grow as a professional group this survey should be repeated.

\section{CONCLUSION}

The majority of CDTs on the GDC register were based in the south east of England. The findings suggest that respondents largely worked in the private sector, which has implications for the nature of their patient base. This study provided evidence that clinical dental technicians were embracing their new status as an occupational group registered with the GDC. Certain core elements of being a professional group such as status in the social and financial order were in place. There is a demonstrable need to negotiate current and future roles with the state, other dental professionals and the public; possibly including extending their scope of practice and developing team working further.

We would like to thank BSSPD for their financial support, Dr Andrzej Juszczyk for his help throughout the project and Miss Diane Dale for her assistance with the mailing.

We would also like to acknowledge the assistance of Mr Paul Carter, Senior Geographical Information Systems Technical Officer, Dept of Geography, University of Portsmouth in the production of Figure 1.

1. Nuffield Foundation. Education and training of personnel auxiliary to dentistry. London: The Nuffield Trust, 1993.

2. Clark R K, Radford D R, Juszczyk A S. Current trends in complete denture teaching in British dental schools. Br Dent J 2010; 208: E10.

3. Rosenstein D I, Empey G, Chiodo G T, Phillips D. The effects of denturism on denture prices. Am J Public Health 1985; 75: 671-672.

4. Hancock N. CDTs find favour. Br Dent J 2008; 204: 656-657.

5. Clark R K. The future of teaching of complete denture construction to undergraduates. Br Dent J 2002; 193: 13-14.

6. Clark R K. The complete denture crisis: a personal view. Eur J Prosthodont Restor Dent 2005; 13: 98-99.

7. General Dental Council. Scope of practice; annual report. London: GDC, 2006.

8. Abbott A. The system of professions: an essay on the division of expert labor. Chicago: The University of Chicago Press, 1988.

9. Larson M S. The rise of professionalism: a sociological analysis. California: University of California Press, 1977.

10. Macdonald K M. The sociology of the professions. London: Sage Publications Ltd., 1995.

11. Ross M K, Ibbetson R S, Turner S. Activity and education of clinical dental technicians: a UK survey. BrDent J 2007: 203: E22.

12. Rantanen T, Könönen M. Dentists and dental technicians as competing suppliers of complete dentures in southwest Finland. Community Dent Oral Epidemiol 1979; 7: 270-273.

13. Ritchie J, Lewis J (eds). Qualitative research practice: a guide for social science students and researchers. London: Sage Publications Ltd., 2003.

14. The Information Centre for Health and Social Care. Executive summary: Adult Dental Health Survey 2009. London: The Health and Social Care Information Centre, 2011. Online article available at http://www.ic.nhs.uk/webfiles/ publications/007_Primary_Care/Dentistry/ dentalsurvey09/AdultDentalHealthSurvey_2009 ExecutiveSummary.pdf (accessed December 2012).

15. The Information Centre for Health and Social Care. Theme 1: oral health and function - a report form the Adult Dental Health Survey 2009. London: The Health and Social Care Information Centre; 2011. Online article available at http://www.ic.nhs.uk/ webfiles/publications/007_Primary_Care/Dentistry/ dentalsurvey09/AdultDentalHealthSurvey_2009 Theme1_Oralhealthandfunction.pdf (accessed December 2012).

16. Borreani E, Wright D, Scambler S, Gallagher J E. Minimising barriers to dental care in older people. BMC Oral Health 2008; 8: 7.

17. Borreani E, Jones K, Scambler S, Gallagher J E. Informing the debate on oral healthcare for older people: a qualitative study of older people's views on oral health and oral healthcare. Gerodontology 2010; 27: 11-18.

18. Borreani E, Jones K, Wright D, Scambler S, Gallagher $J$ E. Improving access to dental care for older people. Dent Update 2010; 37: 297-298, 301-302.

19. General Dental Council. Principles of dental team working. London: GDC, 2006. Online article available at http://www.gdc-uk.org/Newsandpublications/ Publications/Publications/DentalTeamWorking.pdf (accessed December 2012).

20. Lynn A M. Denturism - no objections but... Br Dent J 1985; 158: 160.

21. Illegal dentistry crackdown. Br Dent J 2012; 212: 110 